way a crack, no matter how fine, can scarcely escape detection, and this is attained without severe eye-strain or mental fatigue on the operator. Other advantages which the demonstration exhibited are its applicability, without staining or the necessity for after-treatment, to all metals and to many other materials, its simplicity and cheapness of operation, and the quickness with which the process can be carried out, even on mass-produced articles.

While the normal technique is that of dipping in the fluorescent bath, this can be varied to suit special cases. An exhibit of special interest was a flaw in the interior of the base of an aeroplane propeller blade. The hole had been sprayed with the fluorescent solution and after being washed out, the insertion of a black lamp showed the flaw glowing clearly with fluorescent light. This obviously valuable scientific process was shown in its adaptation to the practical requirements of engineering, but its great possibilities suggest a much wider field of application both in scientific investigation and industrial development.

\section{Magnetic Crack Detectors}

AN article in the Electrical Review of August 28 describes a magnetic detector used to facilitate crack detection in motor and aero-engine parts. While radiographic methods of crack and blow-hole detection possess undoubted advantages when the flaw lies below the surface, for superficial cracks and defects as much as $\frac{1}{1}$ in. below the surface, the magnetic crack detector offers advantages in the speed and economy of its application. The general principles of the method have been described in the Electrical Review of April 4, 1940. They consist briefly of subjecting the part under test to a magnetic field and applying a magnetic powder, or a liquid medium containing such powder, to the suspected surface, so that any polarity due to a crack is rendered visible to the eye by collection of the magnetic particles over it.

The crack detector described, known as the 'Magnaflux' (Equipment and Engineering Co., Ltd.), possesses the special feature of sliding laminated pole tips between which the object is mounted for inspection. A few seconds only are needed to adapt them to objects of almost any shape by morely sliding the laminations up to the contour of the specimen. A further feature is that means are provided for controlling the magnetizing current, which is important on account of the need for avoiding supersaturation, or insufficient saturation. There is an optimum degree of magnetization giving the most readily seen and erisply defined crack outlines. Demagnetization of the tested parts is effected by laying the objects on a horizontal platen magnet, or subjecting them to an A.c. field : demagnetization is practically instantaneous.

\section{Electricity in a Beet-Sugar Factory}

B. Sмiтh has described ( $J$. Inst. Elec. Eng., 89, Pt. 2, No. 10 ; Aug., 1942) the application of electricity in the treatment of sugar beet through all the stages to the ultimate production of pure sugar. Although many factories in (Yreat Britain have applied electricity in the best manner possible within their limited expenditure, yet both in the factory and in the laboratory there still remains much room for further improvement. For example, individual drives could be installed in many places where at present one large unit and line shafting now exist, and pro- vided they are suitably interlocked-especially where elevators and conveyors work in conjunction-would prove a great advantage. Again, the sugar house should be equipped with the best type of sugarspinning centrifugals. Much has been done by the manufacturers in conjunction with the users to improve this class of machinery.

\section{The Electrified Cane-Sugar Factory}

IN a paper on this subject (J. Inst. Elec. Eng., 89, Pt. 2, No. 10 ; Aug., 1942) L. B. Whitaker deals with some of the considerations relating to total electrification of such factories, with special reference to the factory at Gray's Inn, Jamaica. Reasons are cited for the slow adoption of the totally electrified sugar factory in the British Empire as compared with other parts of the world. A brief general description of the processes involved is then given, advan. tages and disadvantages being discussed and some comparison drawn with steam-driven plants. The necessity of having a sugar factory specially designed for all-electric drive is then stressed, and details are given of the general layout of such a plant to obtain the maximum benefits of total electrification. The most suitable type of apparatus to employ is discussed, including notes on power-factor correction and maintenance routine. The paper concludes with examples of typical power consumption and cost of generating current.

\section{Rural Electrification and Research}

AN article by A. G. H. Dent (Electrician, August 21) surveys the necessary and probable trend of rural electrification and research in Great Britain during the post-war construction period. The author opens with a reference to the national education in food values and uses. The national neglect of agriculture is ended, and any positive reconstruction policy must incorporate broad measures of industrial decentralization of agricultural development and of food-or health-education. The article proceeds to define the position and responsibility of the public utility company in such a scheme, stressing that the words 'public utility' imply usefulness to the public as a national service forming an essential part of the social structurè.

The recent introduction into farming of a minimum wage for agricultural labourers of $£ 3$ per week is cited as an incentive for electrical methods of carrying out farming operations on a continually increasing scale; with such a demand will come the need for electrical apparatus and machinery for doing the work. During the last few years, root cooking by electrical methods has been successfully employed, while the electric wash boiler has found application in the boiling of potatoes. There appears to be a demand for a cheap, low-loaded apparatus, of 1-3 kw., designed especially for root cooking. Bottle washing, herb drying, and the provision of hot water for feeds and mashes are also quoted as more recent uses of electricity in farming.

Mention is made of a (G. E. C. (U.S.A.) experiment in which fruit trees and seeds are bombarded by $\mathrm{X}$-rays in an attempt to improve the size, quality and flavour of the fruit. It is thus evident that a technique may be developed for the more intensive electrification of agricultural processes and that changes may be brought about gradually in farming methods. 